\title{
A ARTE DE VIVER JUNTO
}

\author{
EL ART DE VIVIR JUNTOS
}

THE ART OF LIVING TOGETHER

Denise Gisele DE BRITTO DAMASCO ${ }^{1}$

RESUMO: Nessa resenha, discute-se sobre as discriminações vivenciadas em sociedade. Compreende-se que as discriminações geram a ausência de igualdade e a negação de reconhecimento. O que temos em comum? Somos diferentes, contudo iguais. Conceitua-se a discriminação positiva à francesa como políticas e dispositivos que visam estabelecer a equidade, compensando desigualdades a partir de cotas, tendo como alvo uma população específica, instaurando regras para o benefício de determinados grupos. Corroborando nesse aspecto, reflete-se sobre o paradoxo entre a equidade e o mérito, pois acreditar na igualdade de oportunidade pelo mérito, faz com que o indivíduo se sinta discriminado. A escola surge como um espaço aberto, inclusivo, acolhedor, onde os estudantes aprendem a viver em conjunto.

PALAVRAS-CHAVE: Discriminação. Política de ação afirmativa. Igualdade. Reconhecimento. François Dubet.

RESUMEN: En esta reseña, se discute sobre las discriminaciones vivenciadas en la sociedad. Se entiende que las discriminaciones generan la ausencia de igualdad y la negación del reconocimiento. ¿Qué tenemos en común? Somos diferentes, sin embargo, iguales. Se concibe la "discriminación positiva a la francesa" como todas las políticas y los dispositivos que buscan establecer la equidad, compensando desigualdades a partir de cuotas, teniendo como objetivo una población específica, instaurando reglas para el beneficio de determinados grupos. Corroborando ese aspecto, se reflexiona sobre la paradoja entre la equidad y el mérito, pues creer en la igualdad de oportunidades por el mérito hace que el individuo se sienta discriminado. La escuela surge como un espacio abierto, inclusivo, acogedor, donde los estudiantes aprenden a vivir juntos.

PALABRAS CLAVE: Discriminación. Política de acción positiva. Igualdad. Reconocimiento. François Dubet.

ABSTRACT: In this review, we discuss the discrimination experienced in society. It is understood that discrimination generates lack of equality and denial of recognition. What do we have in common? We are different, yet equal. The French approach conceptualizes positive discrimination as all policies and devices that aim to establish equity,

${ }^{1}$ Universidade Católica de Brasília (UCB), Brasília - DF - Brasil. Professora efetiva do Programa de PósGraduação Stricto Sensu - Mestrado e Doutorado em Educação. ORCID: <http://orcid.org/0000-0002-02500776>.E-mail: denise.damasco@gmail.com 
compensating for inequalities based on quotas, targeting a specific population, establishing rules for the benefit of certain groups. Corroborating in this aspect, we reflected on the paradox between the equity and the merit, because to believe in the equality of opportunity by the merit, makes the individual feel discriminated. The school emerges as an open, inclusive, welcoming space where students learn to live together.

KEYWORDS: Discrimination. Positive Action Policy, Affirmative Policy. Equality. Recognition. François Dubet.

\section{Introdução}

Esta resenha apresenta a obra intitulada, originalmente, Ce qui nous unit. Discriminations, égalité et reconnaissance ${ }^{2}$ do sociólogo francês François Dubet, professor da Universidade de Bordeaux II Victor-Ségalen e diretor da École des Hautes Études en Sciences Sociales na França. Sem tradução ainda em português, nos traz elementos para refletir sobre a arte de viver em conjunto. Tema relevante para a área educacional que nos alerta sobre a necessidade de ouvir os indivíduos que se sentem discriminados, tendo em vista que as situações de discriminação são múltiplas, e dificilmente desveladas em sua essência e completude.

O título da obra que propomos em tradução livre: O que nos une. Discriminações, igualdade e reconhecimento, por si só nos remete às diversas situações da vida em sociedade e em instituição escolar, sendo essa temática esmiuçada ao longo das 119 páginas da mesma organizada em quatro capítulos. Após uma Introdução, com o título Iguais e diferentes, outros quatro capítulos se seguem: A prova da discriminação; A discriminação positiva à francesa; Os conflitos de reconhecimento; e A terceira via ausente: reconstruir uma sociedade. Tais capítulos são permeados por indagações provocativas para as quais o próprio autor compartilha com o leitor suas dificuldades de respondê-las, sobretudo, em um contexto francês no qual "as discriminações fazem parte das questões intoleráveis que se transformam em embates ideológicos e políticos para os quais não se há medida nem generosidade" (p. 117).

\footnotetext{
${ }^{2}$ Obra publicada pelas Éditions du Seuil, editora fundada em 1935, cujo objetivo é publicar títulos que permitam compreender questões de nosso tempo, em parceria com La République des Idées, que foi criada por Pierre Rosanvallon em 2002. Rosanvallon também interessado em produzir análises e ideias originais sobre grandes debates. Assim, Seuil e La République des Idées unem-se, dando origem a uma coleção dirigida por Pierre Rosanvallon e Ivan Jablonka com sessenta e oito títulos em 2016, listados em ordem cronológica ao término da obra de Dubet em tela.
}

RIAEE - Revista Ibero-Americana de Estudos em Educação, Araraquara, v. 14, n. 3, p. 1245-1252, jul./set. 2019. E-ISSN: $1982-5587$. 


\section{Apreciação crítica}

Os indivíduos discriminados provocam à sociedade duas questões: a de equidade e a do mérito. Ao se amparar das palavras de Nancy Fraser, François Dubet afirma que "se todas as reivindicações em termos de redistribuição têm consequências em termos de reconhecimento, isto significa que as duas lógicas se encontram sempre associadas, contudo diferentes e, por vezes, contraditórias" (p. 40) ${ }^{3}$.

Dubet nos relembra que as mulheres, as minorias étnicas, culturais e religiosas são discriminadas desde sempre, enfatizando que tais injustiças se tornam invisíveis, como se fossem "normais" (p. 07). Das experiências individuais aos embates coletivos, conclui que "a discriminação é sempre uma prova, uma dor e uma ameaça, porque trinca a fluidez da vida social" (p. 09). Acrescenta o autor que

acreditar na igualdade de oportunidades por meio meritocracia faz com que o indivíduo se sinta discriminado, isso quando não há equidade, como um sujeito que não é responsável por sua própria existência (DUBET, 2016, p. 09).

Ao se questionar sobre o que temos em comum, Dubet propõe uma terceira via, a de construir as instituições, dentre as quais, a escola, para que "seja acolhedora, na qual todos estudantes, qualquer que seja sua origem e ou futuro destino, aprendam a viver em conjunto " (p. 12). Ao lançar a imagem de uma escola como uma estação de triagem, distante de um modelo de escola aberto e inclusivo, o autor critica a escola francesa "como uma máquina de exclusão, hostil àqueles que são muito diferentes” (p. 12). Ao longo de sua carreira, Dubet debruça-se em torno do que significa uma escola justa e uma escola com igualdade de oportunidades ${ }^{4}$.

Para compreender as dificuldades dos indivíduos, Dubet sugere, em seu primeiro capítulo, que não se reduza os mesmos aos estereótipos, nem tampouco suas histórias em clichés, pois não se trata apenas de se colher depoimentos sobre as pessoas que são discriminadas, mas de compreender as situações de discriminações como "fatos objetivos e mensuráveis" (p. 16). Por exemplo, a partir de uma análise estatística, Dubet relata que se viver em um bairro na periferia na França gera mais oportunidades de ser pouco

3 Tradução livre da citação de FRASER, N. apud DUBET, F. Qu'est-ce que la justice sociale? Reconnaissance et redistribution. Paris, La Découverte, 2005, p.67.

4 Tais obras sobre essa temática intitulam-se: L'Ecole des Chances (2004), Les Places e Les Chances. Repenser la Justice Sociale (2009) e La préférence pour l'inégalité. Comprendre la crise des solidarités (2014). 
qualificado, de estar desempregado e de ser controlado pela polícia rotineiramente. A discriminação se revela como uma experiência pessoal e singular, na medida em que "dois indivíduos pertencentes ao mesmo meio e vivendo as mesmas condições podem ter visões e experiências de discriminação bem distintas" (p. 19).

Como desvelar as discriminações? Dubet propõe que "nos aproximemos das experiências dos indivíduos discriminados e daqueles que são ameaçados de sê-lo" (p. 21). Concorda-se com Dubet, quando este afirma que "a experiência com discriminações é tão profunda e tão íntima que é ilusório esperar compreendê-la, quando não se é discriminado" (p. 21). Como solução, Dubet assevera que se lance mão do cinema e da literatura, pois cineastas e escritores compreendem melhor essa temática, suas subjetividades e sutilezas que estão presentes nos olhares, nas questões do corpo, dos gestos, das esquivas e rejeições, ou seja, nas invisibilidades e agressões do cotidiano. A partir dessa constatação, ao trazer a mesma ao campo educacional, destacamos a importância da exposição à cultura e à literatura em instituições escolares, ampliando a oferta curricular sistemática de disciplinas como Artes e Música, oportunizando projetos extracurriculares, artísticoculturais e vivências para além de um currículo que valorize apenas conteúdos e formação profissional.

Ainda nesse capítulo, reflete em como agir e reagir à discriminação, e nas estratégias para que não se sinta rejeitado. Exemplifica por meio daquele que se sente discriminado que se fecha "em seu próprio gueto" (p. 38). O discriminado, muitas vezes, age até "esquivando-se, evitando lugares, pessoas, circunstâncias em que há risco de ser mal recebido, $[\ldots]$ dissimulando, fingindo, usando do humor para desarmar o agressor, prevenindo-se de ameaças potenciais" (p. 39). Aquele que já é discriminado se autodiscrimina ainda mais.

No segundo capítulo da obra, Dubet introduz o termo em francês discrimination positive como políticas e dispositivos que visam assim, estabelecer "a equidade, a compensação de certas desigualdades fixando cotas, focando em uma população determinada e instaurando regras explicitadas para beneficiar grupos específicos"5 (p. 42). De acordo com o Dictionnaire de l'Education $(2008)^{6}$, esse termo que traduzimos ao pé da letra por 'discriminação positiva' abarca duas categorias de políticas de orientação distributiva no contexto francês. A primeira política, como um conjunto de medidas que

\footnotetext{
${ }^{5}$ Tradução nossa.

${ }^{6}$ Destaca-se que François Dubet é o autor dos verbetes 'instituição escolar' e “justiça” no Dictionnaire de l'Education (2008).
}

RIAEE - Revista Ibero-Americana de Estudos em Educação, Araraquara, v. 14, n. 3, p. 1245-1252, jul./set. 2019. E-ISSN: 1982-5587. 
aumenta os recursos às instituições de ensino médio em que há estudantes com menos oportunidades de êxito na escola, e a segunda política, como um conjunto de medidas de oferta seletiva de acesso ao ensino superior, termo que poderia ser traduzido em português como 'políticas de ações afirmativas'.

$\mathrm{O}$ autor problematiza a discriminação positiva à francesa ao questionar sobre a dificuldade em "como focar em grupos discriminados quando mal se reconhece sua existência em espaços públicos $7 "$ (p. 41). Dubet levanta a situação de cidadãos franceses considerados imigrantes, que mesmo sendo franceses há muito tempo, não são reconhecidos como tal, concluindo que "as discriminações e o racismo são uma das consequências da exploração e uma condição da exploração exacerbada de uma parte do proletariado" (p. 44). Nas palavras de Dubet, mesmo que caiam "as fortalezas profissionais reservadas aos homens pelo direito e pelo costume: na justiça, na medicina, na polícia, no exército, etc." ${ }^{9}$ (p. 47), existe ainda um sentimento de discriminação de massa e de discriminação sutil. Para o autor, apesar de a sociedade considerar como um progresso as políticas de alargamento de acesso aos excluídos às profissões e às instituições de ensino, persiste uma discriminação sutil, apesar de haver uma consciência de que seja preciso implementar políticas de ações afirmativas "em nome da igualdade de oportunidades, da representação da sociedade em todos os níveis e da abertura ao mundo" $" 10$ (p. 51).

Dubet alerta que a discriminação positiva, como uma política de acesso ao ensino superior, intitulada no Brasil de política de ações afirmativas, pode ter um efeito negativo sobre aqueles que não fazem parte de nenhuma cota, pois ao se defender o mérito pessoal incontestável, pode-se trazer dúvidas sobre os méritos reais de seus beneficiários. O sociólogo se questiona sobre o quantitativo de queixas sobre racismo e sexismo no contexto francês, acreditando que ainda são parcas as queixas contra o assédio policial: “Como fazer uma queixa contra assédio policial dirigindo-se à polícia, quando não se tem testemunha e quando se é um jovem conhecido já por pequenos delitos?"11 (p. 63). Fazer uma queixa em ambiente profissional significa opor-se ao mundo profissional, colocandose em risco, confirmando os clichês racistas e sexistas já existentes. Assim, diante do

\footnotetext{
7 Tradução nossa. No texto original, o autor apresenta sobre forma de pergunta, que resenhamos como interrogação indireta.

8 Tradução nossa.

${ }^{9}$ Tradução nossa.

${ }^{10}$ Tradução nossa.

11 Tradução nossa.
} 
trauma ao ser discriminado, a recusa em se fazer uma queixa formal pode se tornar uma forma de resiliência e não uma forma de fugir do combate. Para Dubet, "o embate entre igualdade e equidade desemboca em um modelo de justiça muito geral, podendo significar que a equidade não seja suficiente" 12 (p. 67) nesse cenário.

Os conflitos de reconhecimento das identidades e culturas são o tema do terceiro capítulo dessa obra. Compreendendo a demanda por igualdade e equidade como premissa de uma concepção de justiça em uma sociedade democrática, Dubet revela a seguinte contradição: "se a demanda de igualdade leva à invisibilidade, a demanda de reconhecimento leva à visibilidade" (p. 69).

Para Dubet, os princípios de justiça permitem que se definam compromissos e prioridades, enquanto que os valores e identidades não se negociam tão facilmente: “é possível aceitar que alguém acredite ser mais ou menos rico, mas é difícil de ser 'um pouco mais' ou 'um pouco menos' (grifos do autor) francês, católico, muçulmano" (p. 70). Esclarece que a demanda por reconhecimento e identidade procede de um "direito de ser você mesmo" (p. 71) e não um efeito de uma crise ou de um problema social.

Em consequência, surge a importância em torno do que significa nação e natureza. Segundo o autor, a nação não advém apenas de uma situação geopolítica, fruto da democracia e do Estado. É uma adesão a um discurso e a um fato, sendo que uma representação de fraternidade, pode dar consistência e estabilidade contra as desordens do mundo. Para Dubet, "a soberania se compartilha" (p. 75), distanciando-se da tendência de alguns partidos políticos, intelectuais e frações da opinião pública em se fazer os imigrantes e descendentes de inimigos. O autor coloca por terra a ideia de família natural e as relações entre as mulheres e entre os homens: 'o casamento para todos' (grifo do autor) significa "igualdade entre os indivíduos e o reconhecimento da igual dignidade das sexualidades" (p. 75). Explicita que a "família tradicional torna-se uma família possível, 'um tipo de família entre as outras' (grifo do autor); podendo se tornar, inclusive, uma família minoritária” (p. 84).

O último capítulo constata a ausência de uma terceira via para o enfrentamento das discriminações, que seria a reconstrução da sociedade. Afirma que há uma possível solução diante dos impasses e da inação nas quais nos encontramos:

12 Tradução nossa.

RIAEE - Revista Ibero-Americana de Estudos em Educação, Araraquara, v. 14, n. 3, p. 1245-1252, jul./set. 2019. E-ISSN: $1982-5587$. 
nem a generalização das discriminações positivas, ao se pensar em igualdade, nem o multiculturalismo sem princípio, ao se pensar em reconhecimento, não parecem possíveis, desejáveis, nem mesmo desejados pela maioria dos indivíduos discriminados" (DUBET, 2016, p. 97).

O autor compreende os enfrentamentos oriundos dessas questões "mais como sintomas de medo do que como respostas às provas sofridas pelos atores comuns e aos embates coletivos provenientes desse debate" (p. 97).

Assim, uma terceira via é a sociedade construída a partir de uma concepção que repousa em três pilares: "o primeiro pilar é uma representação orgânica da divisão do trabalho e da solidariedade a partir do trabalho, com a interdependência das classes, de suas funções econômicas e sociais” (p. 98). O segundo pilar é constituído pelas instituições. Como exemplo de instituições, o autor cita a escola, que deve "inculcar valores universais e nacionais, preparando o indivíduo para o trabalho" (p. 98). O terceiro pilar é a nação, assentada em uma base comunitária, sobre a qual se tem "um discurso e um imaginário compartilhados, ensinados, ritualizados, incessantemente relançados" (p. 99).

Lutar contra as discriminações exige "primeiramente, uma transformação profunda do sistema escolar, a melhoria sensível da qualidade de oferta escolar nos estabelecimentos mais populares, uma distribuição de recursos para que ninguém fuja das escolas da periferia e das carreiras menos favorecidas" (DUBET, 2016, p. 104).

\section{Considerações finais}

Como viver em conjunto sendo diferentes? A partir do contexto francês contemporâneo, Dubet nos faz compreender as relevâncias das singularidades das pessoas discriminadas. Destaca a necessidade de afirmação do direito, das convenções, das cartas, das associações e do acesso à informação como procedimentos de promoção de equidade. O embate sobre o reconhecimento provoca discussões político-ideológicas que são amplas e genéricas, em oposição às experiências intensas dos indivíduos que se encontram sem reconhecimento, continuamente discriminados.

A reconstrução de uma sociedade, como lócus onde problemas possam ser negociados, gerando compromissos é uma possibilidade para vencer esse desafio. Em uma sociedade movida pelo pânico e pelo medo, a partir da obra de Dubet compreende-se que é "preciso escolher a experiência dos indivíduos em detrimento de doutrinas políticas", ou 
seja, "se a democracia é a arte de viver em conjunto, é preciso renovar a representação democrática, reconstruir a igualdade social, construir instituições acolhedoras e escrever um outro discurso nacional" (p. 119).

AGRADECIMENTOS: à Embaixada da França no Brasil, que em 2011 me proporcionou uma bolsa de estágio doutoral na Universidade de Bordeaux II Victor-Ségalen, onde tive oportunidade de conhecer o sociólogo François Dubet, compartilhar com o mesmo meu objeto de pesquisa doutoral e refletir sobre o que significa uma escola justa com igualdade de oportunidades.

\section{REFERENCIAS}

DUBET, François. Ce qui nous unit. Discriminations, égalité et reconnaissance. Paris : Seuil-La République des Idées, 2016, p. 119.

VAN ZANTEN, Agnès (sous la Direction de). Dictionnaire de l'éducation. Paris: Presses Universitaites de France, 1. ed., 2008.

\section{Como referenciar}

DAMASCO, Denise Gisele de Britto. A arte de viver junto. Revista Ibero-Americana de Estudos em Educação, Araraquara, v. 14, n. 3, p. 1245-1252, jul./set. 2019. E-ISSN: 1982-5587. DOI: 10.21723/riaee.v14i3.12368

Submetido em: 20/02/2019

Revisões requeridas: 10/03/2019

Aceito em: 12/04/2019

Publicado em: 11/05/2019 